\title{
A Educação do Campo no Semiárido Mineiro e o LabÉdoCampo
}

\author{
Heiberle Hirsgberg Horácio ${ }^{1}$ \\ Laura Patrícia Aguiar Cardoso ${ }^{2}$ \\ Tamires Pereira de Jesus Souza ${ }^{3}$
}

ENTREVISTA realizada com as professoras Magda Martins Macêdo, Maria Auxiliadora Amaral S. Gomes, Maria Aparecida Afonso Oliveira e Roberta Bangioni Fontes, que são integrantes e parceiras do Laboratório de Educação do Campo no Semiárido Mineiro: Diversidade, Território, Agroecologia (LabÉdoCampoSemiáridoMineiro),

\section{Apresentação}

Desde o ano de 2014 o Laboratório de Educação do Campo no Semiárido Mineiro: Diversidade, Território, Agroecologia (LabÉdoCampoSemiáridoMineiro) existe como um projeto na Universidade Estadual de Montes Claros (UNIMONTES), "o qual busca ser um espaço de trocas de saberes entre a universidade e sujeitos do campo". (MACEDO etall, 20184). O LabÉdoCampo, como é conhecido, tem como princípios metodológicos as concepções e ferramentas da Educação Popular e da Pedagogia do Oprimido, primando por relações dialógicas, conscientizadoras e libertadoras.

O LabÉdoCampo/ Unimontes, “juntamente com movimentos sociais populares, IFEs regionais, ongs e entidades de classe compõem a Articulação Por uma Educação do Campo no Semiárido Mineiro" (MACEDO etall, 2018), a Rede Mineira da Educação do Campo, bem como a Comissão Permanente da Educação do Campo na SEE/MG.

\footnotetext{
${ }^{1}$ Pós-Doutor em Ciências Sociais. Professor do Programa de Pós-Graduação em Educação, do Depto de Filosofia e do curso de CRE da Universidade Estadual de Montes Claros. Minas Gerais, Brasil. heiberle@ hotmail.com. Orcid: https://orcid.org/0000-0002-4486-1764.

${ }^{2}$ Mestranda em Educação. Professora efetiva de Ensino Religioso do Estado de Minas Gerais. Minas Gerais, Brasil. laurapatriciaaguiarcardoso@yahoo.com.br. Orcid: https://orcid.org/0000-0003-1976-6527.

${ }^{3}$ Mestranda em Educação. Minas Gerais, Brasil. tamirespereira521 @ gmail.com. Orcid: https://orcid.org/0000-0003-1849-9340.

${ }^{4}$ Ver: https://proceedings.science/cied/trabalhos/a-atuacao-do-labedocampo/unimontes-em-uma-escolade-assentamento-do-mst\%3A-possibilidades-e-desafios. (Acesso em 12/07/2021).
} 


\section{Edurañugsiscolarsociedace}

Fazem parte do projeto, direta ou indiretamente, professoras e professores de diferentes departamentos da Unimontes, de diferentes escolas, egressas e egressos dos cursos da Unimontes, acadêmicas, acadêmicos, pesquisadoras, lideranças de diferentes movimentos, e diferentes pessoas envolvidas na luta pela Educação do Campo.

O projeto é coordenado pela Profa. Magda Martins Macêdo - do Depto de Educação/Unimontes, da coordenação da Rede Mineira de Educação do Campo e do FONEC, da Comissão Permanente da Educação do Campo CPEC/SEE MG, RESAB, e do Coletivo de Educação, Arte e Cultura/MST Norte de Minas -, e possui entre as integrantes a Profa. Maria Auxiliadora Amaral S. Gomes (DMTE/Unimontes, PPGE, Rede Mineira, CPEC/SEE MG). Como Articulação Por uma Educação do Campo no Semiárido Mineiro, assim como do LabÉdoCampo, contamos nessa entrevista com Maria Aparecida Afonso Oliveira (Educadora Popular, coordenadora do CONACREJE em Jequitinhonha, integrante da Rede Mineira, parceira do LabÉdoCampo), e Roberta Bangioni Fontes (Educadora popular, escritora, doutoranda PPGDS, bolsista CAPES, parceira do LabÉdoCampo e Coletivo de Educação, Arte e Cultura/MST Norte de Minas).

Conversamos com elas sobre Educação do Campo e sobre o curso de Pedagogia da Terra, que está em processo de criação na Unimontes. Vejam a seguir:

\section{1- Professoras, como se deu o processo de constituição do LabÉdoCampo na} Unimontes, suas temáticas centrais e quais as ações realizadas?

A Unimontes assume efetivamente o debate da Educação do Campo no ano de 2006 ao aprovar junto ao Programa Nacional de Educação na Reforma Agrária (PRONERA) ${ }^{5}$, os cursos de Magistério do Campo/Nível Médio e Agroecologia e de Alfabetização e Escolarização de Jovens e Adultos Assentados, como fruto de dois anos de diálogo e mobilização junto às comunidades campesinas regionais norte mineiras, sejam assentadas, acampadas e das comunidades tradicionais. O PRONERA representa um marco no que diz respeito ao avanço da efetivação conceitual, legal e das políticas públicas para o atendimento escolar oficial e público para as populações rurais, em todo o Brasil. Em seguida se desenvolveu a Licenciatura em Pedagogia do Campo e um curso de pós-graduação lato sensu na perspectiva da Educação à Distância (EAD), por

${ }^{5}$ Primeira política pública educacional criada com o objetivo do atendimento educacional das populações da reforma agrária na perspectiva da Educação do Campo. Criada em 1998. 


\section{EdurañärEscolar Sociedlace}

meio da Universidade Aberta do Brasil (UAB), com o curso de especialização em Educação do Campo.

Entre os anos de 2011 e 2014 foi desenvolvido o Projeto de Pesquisa "É do Campo", composto por professores e acadêmicos do curso de Pedagogia, e ainda contou com uma diversidade de sujeitos do campo envolvidos no Grupo de Estudos e na Oficina de Metodologias Participativas, ações previstas no desenvolvimento da pesquisa.

Depois um grupo de professores e acadêmicos da Unimontes, educadores regionais, populações tradicionais como geraizeiros, quilombolas, vazanteiros, movimentos sociais do campo, entidades não governamentais, participaram da elaboração coletiva do livro paradidático Opará e Jequi - os Saberes dos Vales, após convite da Rede de Educação do Semiárido Brasileiro (RESAB) em parceria com o Instituto Nacional do Semiárido (INSA), para participação em uma das quatro Oficinas de Produção de Materiais Paradidáticos, do CNPQ, propostas em quatro locais do Semiárdo Brasileiro, dentre eles no Norte de Minas, em Montes Claros.

Essa ação coletiva de produção do livro paradidático fez surgir a Articulação Por uma Educação do Campo do Semiárido Mineiro, em que a Unimontes faz parte e, assim, realiza em 2012, o I Seminário Regional de Educação do Campo e Ruralidades (I SER). Já em 2013, foi realizado também numa ação coletiva com a Articulação Regional, o I Encontro de Pesquisa e Prática em Educação do Campo, Educação Contextualizada e Convivência com o Semiárido Mineiro (I EPPECSAM). No ano de 2016, concluiu-se o livro paradidático Opará e Jequi: os Vales e seus Saberes, conduzindo encontros de lançamento do livro e efetuando sua distribuição em Escolas do Campo, Universidades, IFE's e entidades parceiras.

Dando seguimento ao percurso pelas diversas temáticas e diversos sujeitos imbricados com a Educação do Campo é que se propôs então a criação do projeto do Laboratório de Educação do Campo no Semiárido Mineiro: Diversidade, Território, Agroecologia (LabÉdoCampoSemiáridoMineiro), o qual tratou de LabÉdoCampo, no ano de 2014, dando assim continuidade ao compromisso da Unimontes com essa área do conhecimento na região. 


\section{EdurañärEscolar Sociedlace}

Quanto às temáticas centrais de atuação do LabÉdoCampo, existem atualmente sete Linhas de Atuação que se articulam e propõem discussões sobre Educação, Semiárido Mineiro, Cultura, Território, Trabalho, Sustentabilidade, Tecnologias da Informação e da Comunicação (TIC's), dentre outras, tendo como eixo integrador o debate sobre as políticas públicas da Educação para as comunidades do campo.

Ao longo desses anos o LabÉdoCampo vem se consolidado como principal articulador e fomentador de ações vinculadas à temática da Educação do Campo tanto dentro da Unimontes, universidade onde se insere, como na região do semiárido mineiro. Dentre as ações do LabÉdoCampo destacamos o Grupo de Estudos Interdisciplinares e Articulados (GÉIA);o Desenvolvimento de Iniciação Científica, produção de trabalhos científicos, trabalhos de conclusão de curso (TCC) e participação em eventos científicos e outros eventos promovidos pelas organizações sociais campesinas; o fortalecimento da Articulação Por uma Educação do Campo no Semiárido Mineiro; o planejamento, a organização e a execução do II Seminário Educação do Campo e Ruralidades no Semiárido Mineiro (II SER SEMIÁRIDO) e por fim a elaboração do Projeto do Curso de Licenciatura em Pedagogia da Terra, na perspectiva da Pedagogia da Alternância, a fim de formar professores para atuarem na Educação Infantil, nos Anos Iniciais do Ensino Fundamental e EJA, suprindo uma lacuna na formação dos professores do campo no Semiárido Mineiro.

\section{2- Qual a relação da Educação do Campo com a perspectiva pedagógica de Paulo} Freire? Como podemos relacionar os saberes populares e os saberes científicos na Educação do Campo?

A Educação do Campo surgiu na década de 90, como reivindicação por uma educação contextualizada e libertadora para as populações do campo, sobretudo motivada pela necessidade de assegurar a educação nas áreas da Reforma Agrária, a partir de uma proposta que estivesse em consonância com o projeto político pelo qual o Movimento dos Trabalhadores Rurais Sem Terra - MST lutava, junto a outros movimentos sociais do campo e seus parceiros.

Logo, a Educação do Campo concebe sua proposta pedagógica a partir de um acúmulo que esses movimentos já traziam em relação a diversas inspirações pedagógicas da vertente crítica, dentre as quais podemos citar o movimento de educação popular, com a pedagogia do oprimido e todo o legado de Paulo Freire, que emergiram 


\section{EdurañärEscolar Sociedlace}

na década de 50 e seguiram influenciando fortemente o pensamento dos movimentos sociais nas próximas décadas. Junto a essa perspectiva, somaram-se outras para a consolidação do conjunto de fundamentos e práticas que compõem hoje a Educação do Campo, como a Pedagogia Socialista, a Pedagogia da Alternância e a própria Pedagogia do Movimento.

Então, como indica Conceição Paludo, no Dicionário de Educação do Campo (2012, p. 283), podemos afirmar que a Educação do Campo se vale de elementos seminais da educação popular, os atualiza e avança em algumas formulações, articulando-as em relação a um público específico: as populações do campo, em toda sua diversidade e complexidade.

Para elencarmos alguns princípios e práticas freirianas que estão presentes na Educação do Campo, podemos citar: a dialogicidade; a organização e protagonismo popular; a práxis; a inter-relação profunda entre a educação, a cultura e a política; a orientação do processo educativo voltado para a conscientização e a transformação da realidade; o uso de metodologias como o círculo de cultura, o teatro do oprimido, o método ver-julgar-agir.

Esses princípios e práticas permeiam como norteamentos teóricos a construção dos projetos político-pedagógicos, das ementas e da organização curricular dos cursos de Pedagogia da Terra, das Licenciaturas em Educação do Campo, das escolas do campo, de diversos projetos e ações ligadas ao movimento da Educação do Campo. Da mesma forma, se fazem presentes na prática pedagógica, num processo nunca pronto e perfeito, mas em constante construção e aperfeiçoamento, em luta para não sucumbirem aos condicionamentos e desafios impostos pelo sistema educacional hegemônico.

O legado do pensamento freiriano para a Educação do Campo, também é nítido na forma como esta trabalha a relação entre os saberes populares e os saberes científicos, pois na medida em que a Educação do Campo reconhece o valor do saber que cada pessoa/cultura traz consigo, o papel do professor como um mediador, a dialogicidade e o protagonismo popular, busca-se construir uma relação de diálogo e horizontalidade entre os saberes acadêmicos e os saberes populares.

Não cabe uma postura em relação à ciência como a que é tradicionalmente veiculada pelo modelo de educação hegemônica, em que a ciência ocidental é apresentada como forma única de conhecimento válido e superior aos demais sistemas 


\section{Edurañugsiscolarsociedace}

de conhecimento. Portanto, é necessário que em cada território educativo, educadores e educandos do campo busquem conhecer os saberes locais populares, sua biodiversidade, sua cultura - formas de conhecer, plantar, colher, cozinhar, preservar, curar, cuidar das águas, das sementes, dos animais, suas danças, cantos, crenças, histórias, ofícios - e acolham esses saberes de forma fecunda e criativa nos espaços escolares e acadêmicos. A educação do campo, comprometida com o chão das lutas de seus sujeitos, não pode prescindir desses saberes, que são formas de viver e resistir.

Tal postura não implica um movimento de desconsiderar o papel da ciência moderna e suas conquistas, sobretudo em um tempo em que, diante de tanto obscurantismo, é necessário defende-la. Porém, trata-se de olhá-la a partir de uma perspectiva crítica, seja na ótica da tradição marxista, quanto por outros caminhos que vêm sendo apontados pelo pensamento crítico latino-americano, como os debates sobre a descolonização do saber, do poder e do ser.

Enfim, podemos dizer que a perspectiva freiriana, está entre os pilares que fundamentam a Educação do Campo, não de forma engessada, mas sim, dinâmica e constantemente atualizada na história em movimento das vidas e lutas dos sujeitos do campo historicamente oprimidos, que buscam a educação como prática da liberdade.

\section{3- Professoras, há dados que indicam o fechamento de muitas escolas do campo} nos últimos anos. Como isso afeta as comunidades e os estudantes que precisam se deslocar para centros urbanos em busca de estudos? E quais as lutas e conquistas nesse sentido?

Historicamente "a Educação do Campo tem-se pautado por uma matriz formativa ampliada que comporta diferentes dimensões do ser humano" (Molina, 2017, p. 5). Deste modo, a escola do campo precisa considerar em seu projeto políticopedagógico uma proposta que vá além do ensino-aprendizagem, mas que também contribua para formar uma consciência política, valores éticos, habilidades para a vida. Desenvolver uma formação humana, contrariando a lógica forjada sob a égide capitalista que quer apenas ofertar uma educação mercadológica. Neste sentido, a escola que se almeja no campo deve contribuir para formar camponeses e camponesas sob uma perspectiva crítica, que sejam motivados a se tornarem protagonistas de sua própria história. Uma escola em que suas marcas se espalhem pelo chão da vida. De uma vida camponesa com dignidade e justiça social. 


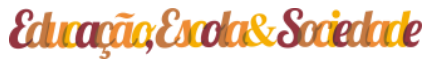

A Educação do Campo bem como a Escola do Campo, podem possibilitar diversas situações transformadoras no campo, ao promover uma gestão popular e compartilhada, trabalhar a dimensão humana para além do sistema imposto pela lógica capitalista e mercadológica, construir estratégias de desenvolvimento sustentável e solidário no campo, dentre outras alternativas possíveis.

Neste sentido, a política de fechamento de escolas do campo em curso no Brasil, faz parte de um projeto contrário à Educação do Campo. Tem a ver com o interesse de grandes empresas, do agronegócio, de um sistema que busca esvaziar o campo, para então tomá-lo. Outro fator de interesse é a concentração de terras e água, dessa forma, fechar escola é possibilitar cada vez mais o esvaziamento do campo, dando lugar ao avanço do agronegócio. Muitos gestores alegam a economia ao fechar tais escolas, mas ao mesmo tempo investem muito recurso em transporte escolar, ainda que sejam precários. O que também motiva o fechamento é desvalorização do campo, decorrente de um modelo fundiário, onde a educação historicamente foi relegada ou tratada perifericamente na legislação educacional ou abordada sob crivo de preconceito e estereótipo.

Nos últimos 20 anos, 146.232 escolas foram fechadas no Brasil, sendo 100.961 escolas do campo e 45.271 nos territórios urbanos (Geperuaz, Censo Escolar do INEP, 2000-2020). Infelizmente, há uma política de nucleação no campo, apoiada por gestores públicos que atuam para que os educandos se distanciem cada vez mais de suas comunidades, seja intracampo, ou indo para a cidade, em transportes precários e percorrendo distâncias bem cansativas. A nucleação contribui para avançar o fechamento das escolas no campo, e, muitas vezes, diante de tanta dificuldade com transporte escolar e os impactos causados no cotidiano dos educandos, algumas famílias acabam enviando seus filhos para morarem na cidade.

Neste sentido, pode-se dizer que a nucleação é o principal fator que impulsiona o fechamento das escolas. Ao reunir estudantes em um só estabelecimento cria-se o panorama para extinguir as escolas localizadas próximas as residências das famílias camponesas. O processo de Nucleação de Escolas promove, consequentemente, o transporte escolar precário como forma de lucro nos municípios. Os gestores educacionais fecham escolas de forma indiscriminada com a justificativa que é mais econômico transportar crianças e jovens para um só estabelecimento do que manter escolas funcionando em diferentes localidades. 


\section{EdurañärEscolar Sociedlace}

No ano de 2014, houve a instituição da Lei de $\mathrm{n}^{\mathrm{o}} 12.960$ sancionada pela presidenta Dilma Rousseff. Esta lei alterou a Lei no 9.394, de 20 de dezembro de 1996, a qual estabelece as diretrizes e bases da educação nacional, para fazer constar a exigência de manifestação de órgão normativo do sistema de ensino para o fechamento de escolas do campo, indígenas e quilombolas. No entanto, um dos desafios é a fiscalização e o efetivo cumprimento da Lei nos municípios, pois mesmo tendo a necessidade do diálogo e aprovação das comunidades escolares, gestores ainda continuam desconsiderando o que está previsto em Lei, uma vez que estados e municípios tem autonomia de legislar sobre a sua educação no âmbito do seu território. Assim, pode-se refletir que pouco desacelera o fechamento das escolas, já que continua acontecendo.

O cancelamento das atividades escolares no campo ocorre, ainda, sob o argumento da falta de qualidade do ensino em classes multisseriadas característica marcante das escolas do campo e, sob o pretexto de que não dá para manter escola funcionando com um baixo número de educandos. Entretanto, não há nenhuma Lei, seja em âmbito Municipal, Estadual ou Federal, que estabeleça o número mínimo de estudantes para o funcionamento de uma turma ou escola do campo.

A falta de pertencimento da comunidade à escola, a dificuldade que escola possui em promover maior interação com comunidade escolar, esvaziamento do campo por interesses capitalistas, são fatores que continuam contribuindo para o projeto de esvaziamento do campo. Diante disso, alguns gestores chegam às comunidades com a decisão já tomada para fecharem as escolas, alegando diversas questões que desconsideram o direito dos povos do campo a uma Educação do e no Campo. Mesmo com esses desafios, há municípios em que a população se mobiliza e consegue impedir o fechamento e até mesmo reabrir escolas que foram fechadas, baseando-se na lei e outros fatores qualitativos sobre a importância da escola no campo.

As escolas camponesas são um centro de referência cultural, um local agregador das relações entre famílias, gerações, vizinhos. Especialmente, é um espaço político que promove a presença do governo na comunidade. A escola é da comunidade, a comunidade é da escola. Valoriza a formação cultural e social dos sujeitos campesinos, ao promover interação local e uma educação contextualizada a partir da realidade local. Fortalece, sobretudo, a identidade dos camponeses e camponesas. 


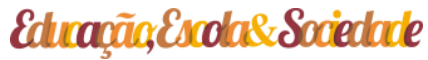

Outro desafio é o livro didático que adentra as escolas do campo, em sua maioria trazendo uma realidade do mundo urbano e de outras realidades que muitas vezes pode impedir uma leitura crítica do contexto local/regional. O PNLD Campo buscou suprir essa carência, mas teve curta duração, sendo criado em 2011 e extinto em 2018. São práticas de apagamento da cultura camponesa, que acabam ganhando espaço perante comunidades que muitas vezes não possuem conhecimento acerca de seus direitos. $\mathrm{O}$ fechamento das escolas do campo denota um exemplo da negação de direitos, ainda mais porque rompe com os vínculos sociais entre a comunidade e a escola.

Importante ressaltar que, a valorização e manutenção da escola no campo podem influenciar na formação cultural e social da comunidade, fazendo com que os sujeitos despertem um olhar mais crítico sobre o seu entorno e possivelmente se tornando mais capazes de promover mudanças e transformações sociais. A escola é vida na comunidade.

Diante disso, a garantia de direitos deve acontecer em conjunto com aqueles que deles necessitam, em um processo de escuta dos desejos, necessidades, sonhos, enfim, considerar os modos de vida das comunidades do campo. Os povos camponeses têm direito de conviver e participar da vida de suas comunidades, terem acesso ao lazer, saúde, escola de qualidade e contextualizada em uma perspectiva crítico-emancipatória. Dessa maneira, a escola, importante instrumento, precisa ser construída junto com a comunidade. Seu fechamento, sem diálogo, sem escuta, é como acabar com um córrego onde corre água essencial à vida no campo. Promove apagamento da cultura, dificulta a aprendizagem dos educandos e interfere nos afazeres da família quando muitas vezes precisam acordar de madrugada e levarem seus filhos até o ponto de ônibus mais próximo.

Com o propósito de garantir a efetivação do direito a uma educação de qualidade aos povos do campo, há muitas iniciativas de luta por diversos coletivos pelo Brasil. Além de Fóruns e Redes nos estados, estes atuam em conjunto com o Fórum Nacional de Educação do Campo - FONEC. Em Minas Gerais, há a Rede Mineira de Educação do Campo, além de outras iniciativas como Conselhos Consultivos das Licenciaturas em Educação do Campo, movimentos sindicais, Laboratórios, a exemplo da Unimontes com o LabÉdoCampo e a Articulação por uma Educação no Semiárido Mineiro. O Movimento dos Trabalhadores Rurais Sem Terra - MST tem cumprido um importante papel nesta luta. No ano de 2011, o MST lançou uma Campanha Nacional contra o 


\section{Edurañugsiscolarsociedace}

fechamento de escolas com o tema "Fechar Escola é Crime", a qual visa discutir e denunciar a situação do fechamento das escolas em especial, no campo, bem como defender a educação pública como um direito de todos os trabalhadores e trabalhadoras.

\section{4- Quais as desafios enfrentados atualmente na efetivação da formação humana, profissional e política da Educação do Campo? E qual a importância do curso de Pedagogia da Terra na Unimontes para a transformação social do Semiárido Mineiro bem como da própria universidade como instituição pública estadual?}

No final dos anos 1990, início da década de 2000 até meados da década de 2020, por cerca de 20 anos, nos encontrávamos em um contexto político mais favorável ao avanço do reconhecimento dos direitos e demandas dos povos, das comunidades campesinas e então à materialização de diversas ações educacionais e de formação humana, técnica e política da Educação do Campo, tais como o atendimento à Educação de Jovens e Adultos -especialmente em seu processo de alfabetização -, a criação da graduação em Pedagogia da Terra e poucos anos depois das Licenciaturas da Educação do Campo (LEC), do programa Escola da Terra - que atendia a especificidade das escolas multisseriadas do campo -, dos cursos de Residência Agrária Jovem, ainda dos Cursos Médios em Agropecuária, Agroecologia, nos institutos federais, dentre outros. Ações essas realizadas via recursos públicos do PRONERA, do PRONATEC Campo, do PROCAMPO, Programas Escola da Terra e Saberes da Terra, todos realizados em parceria com os movimentos sociais do campo e instituições universitárias. Para se ter uma ideia da importância dessas políticas de formação, por exemplo, somente o PRONERA atendeu quase 192 mil estudantes do campo em parceria com mais de 100 mil instituições, em seus 20 anos de existência completados em 2018 (Memórias dos 20 anos da Educação do Campo e do PRONERA, 2018, p. 33).

Nesse momento, não podemos deixar de ressaltar aqui que nos últimos anos, diante da crise política em que se encontra o nosso país, onde as prioridades do governo atual do presidente Jair Bolsonaro se voltam para o projeto do capital - de privilégios dos ricos e da elite brasileira, que têm espoliado e vendido o nosso país para o capital estrangeiro, gerando morte em larga escala (genocídio da pandemia COVID 19), violência contra os povos originários, as comunidades tradicionais e acampamentos sem terra, a criminalização dos movimentos sociais, com o aprofundamento da pobreza, da fome e da desigualdade em todo o nosso país. E tudo isso em detrimento da soberania 


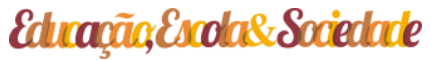

nacional, do respeito à nossa imensa diversidade e riqueza bio-étnico-cultural, da justiça social e ambiental, de um projeto popular de Brasil.

Nesse sentido, as políticas de formação humana, sejam escolares ou nos diversos territórios educativos da Educação do Campo, e também da Educação Quilombola e Indígena, têm sido negligenciadas, desestruturadas, inabilitadas para dar continuidade aos necessários projetos de formação humana, profissional e política das crianças, jovens, adultos, anciãos, sejam mulheres, homens, LGBTQIA+, projetos estes que intencionassem, sim, a autonomia e a libertação do jugo dos opressores dos povos campesinos em todo o Brasil.

Para materializar tal descaso e negligência trazemos o caso do PRONERA, como principal política da Educação do Campo, "Se em 2008 o programa contava com uma cifra de mais de 70 milhões, seu orçamento aprovado na Lei Orçamentária Anual(LOA) de 2018 foi de apenas R\$ 3.203.872,00 (Memórias dos 20 anos da Educação do Campo e do PRONERA, 2018, p. 33).

Vale, nesse momento, apresentar aqui outra concepção educativa, de formação humano-política dos sujeitos do campo na perspectiva Educação do Campo: a Pedagogia do Movimento, construída historicamente na práxis das experiências do MST em sua luta por direitos, nos idos dos anos de 1980/1990.

A Pedagogia do Movimento traz a concepção de que os processos humanos são em sua essência educativos já que se constituem e conformam diante das necessidades humanas, em seu desafio do ser mais, no processo de libertação e conscientização de si e do mundo como sujeitos de direitos (Freire), em um contínuo movimento histórico e contextualizado na luta por uma realidade mais justa e para todos. Daí que o Movimento da Educação do Campo compreende que, para além do território educativo da Escola do Campo, há os outros territórios e momentos educativos constituídos na dinâmica da própria vida na família, na comunidade, no assentamento, no acampamento - daí que coletivos -, em sua luta por terra, por agroecologia e também por uma educação e escola libertadora, com intencionalidades formativas, culturais e políticas enraizadas no lugar de vida, e para além dele, no mundo. 


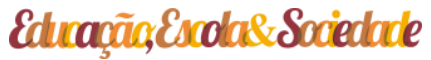

Agora, vamos tratar da Pedagogia da Terra na Unimontes. Como já afirmado anteriormente, a Unimontes já realizou diversos cursos de formação de professores do campo. O LabÉdoCampo, como vimos, foi criado na Pró-Reitoria de Ensino (PRE), já visando sua centralidade na perspectiva da formação humana, e profissional, e política, enredando os temas da Educação com as temáticas da Educação do Campo como educação e reforma agrária, educação e escola do campo como direito, educação e agroecologia, dentre outros. Contudo, nosso maior sonho como demanda histórica a ser materializada era a oferta de um curso de formação dos professores do campo, a Pedagogia da Terra, agora como curso regular na Unimontes.

Assim, nos últimos seis anos desde o ano de 2014, e já como LabÉdoCampo/Unimontes, e também como Coletivo de Educação, Arte e Cultura do MST Norte, temos realizado e participado de inúmeros encontros, reuniões, eventos, tempos-comunidade das LEC's. Nesses momentos coletivos realizados pela Articulação Por uma Educação do Campo no Semiárido Mineiro, MST Norte de Minas, LEC's, EFA's, mandatos parlamentares coletivos e participativos, vimos fazendo a escuta apresentada como demanda à Unimontes como universidade pública com ampla capilaridade regional, da criação de um curso de formação de professores do campo. Tal curso atenderia assim os jovens e adultos vindos das escolas de Ensino Médio das muitas comunidades campesinas, quilombolas e quiçá indígenas, que compõem o vasto território do Semiárido Mineiro, a princípio.

Ao se perguntarem então por que Pedagogia da Terra e não uma Licenciatura em Educação do Campo (LEC)? A identidade da licenciatura de Pedagogia é a formação da professora e professor no atendimento à Educação Infantil, ao Ensino Fundamental (anos iniciais) e EJA, diferentemente das outras licenciaturas, como também as da Educação do Campo, que formam para o atendimento nos anos finais do Ensino Fundamental e Ensino Médio. Para nós, a opção por um curso de Pedagogia da Terra intenciona a formação de professores do campo no atendimento das crianças e jovens do campo em seus momentos iniciais de escolarização, e também trazer ao centro a EJA como urgência da dívida histórica e tão negligenciada na última década. Outra intencionalidade política complementar é estabelecer uma aproximação estratégica da Articulação da Educação do Campo - e também como universidade -, com as instâncias gestoras educacionais municipais, contribuindo no reconhecimento da Educação do 


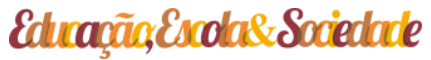

Campo como direito, na efetivação de suas políticas públicas e nos fortalecer contra o fechamento das Escolas do Campo e lutar pela abertura de novas escolas.

Como a Pedagogia da Terra pode contribuir com a transformação social do Semiárido? A resposta para nós está clara. E vamos trazer então aqui o Professor Paulo Freire e a Pedagogia do Oprimido, que nos afirma que "educar é um ato político", que nos educamos uns com os outros, mediatizados pelo mundo, que é na dialogicidade, que é na problematização da realidade próxima como "temas geradores" ou "palavrassementes", como nos diz o Professor Carlos Rodrigues Brandão. Enfim, que é na busca coletiva de caminhos para a resolução dos desafios de determinado espaço e tempo histórico que nos conscientizamos e nos libertamos do jugo da alienação, nos tornando sujeitos da história, em cada comunidade, assentamento, acampamento, e com nossos novos saberes e fazeres, transformamos o mundo. É o que esperamos da Pedagogia da Terra: a trans-formação dos jovens e adultos camponeses em sujeitos de direito com a vontade e coragem para trans-formar a escola do campo, seus lugares e o mundo na luta contra o capital, o autoritarismo, o preconceito, a desigualdade social.

Enfim, entendemos que é no acesso dos jovens e adultos do campo à Universidade -ainda "latifúndio do saber"- como protagonistas, sabedores, criadores, fazedores da práxis de um curso que se materializará como construção e gestão coletiva, democrática e transformadora do mundo em mais justo, que contribuiremos com a tão necessária, e que cremos possível, transformação e justiça social, hoje tão urgente que vale a própria possibilidade de futuro para a humanidade. 